\title{
Influence of nonionic surfactants and water activity on to adsorption of 6-thioguanine at the mercury/chlorates(VII) interface
}

\author{
Agnieszka Nosal-Wiercińska ${ }^{1}$ (i) - Waldemar Kaliszczak ${ }^{1}$ Anna Drapsa ${ }^{1} \cdot$ Mariusz Grochowski $^{1}$ • \\ Małgorzata Wiśniewska $\cdot$ Tomasz Klepka ${ }^{3}$
}

Received: 25 October 2018 / Revised: 11 December 2018 / Accepted: 15 December 2018 / Published online: 27 December 2018

(c) The Author(s) 2018

\begin{abstract}
The mixed adsorption layers of 6-thioguanine-TritonX-100 and 6-thioguanine-Tween 80 formed at the electrode/chlorate(VII) interface are discussed. The systems were characterized by measurements of differential capacity, zero charge potential, and surface tension at this potential. It was found that 6-thioguanine dominates in the formation of adsorption equilibria of the studied mixture. Competitive adsorption between 6-thioguanine-Triton X-100 and 6-thioguanine-Tween 80, $\mathrm{ClO}$ ions or mixed micelles cannot be excluded.
\end{abstract}

Keywords Mixed adsorption $\cdot$ Differential capacity $\cdot$ Nonionic surfactants $\cdot 6$-Thioguanine $\cdot$ Water activity

\section{Introduction}

Studies of organic molecules adsorption on the electrodes constitute a major area of the electrochemical surface research. The properties of electrode surfaces are substantially modified by adsorbed molecules which strongly affect electrode reactions. Such information can be applied for improvement of energy transformation processes (Zeng et al. 2017), elaboration of corrosion inhibitors ( $\mathrm{Qu}$ and Guo 2005; Fouda et al. 2017), control of metals electrodeposition (Taffa et al. 2015) as well as in various electroanalytical techniques (Nosal-Wiercińska 2014).

According to the literature reports formation of mixed adsorption layers on the mercury electrode surface is associated mainly with the competitive adsorption (Munoz et al. 1992; Fuchs-Godec 2007; Nieszporek et al. 2012;

Agnieszka Nosal-Wiercińska

anosal@ poczta.umcs.lublin.pl

1 Faculty of Chemistry, Department of Analytical Chemistry and Instrumental Analysis, Maria Curie-Sklodowska University, M. Curie-Sklodowska Sq. 3, 20-031 Lublin, Poland

2 Faculty of Chemistry, Department of Radiochemistry and Colloids Chemistry, Maria Curie-Sklodowska University, M. Curie-Sklodowska Sq. 3, 20-031 Lublin, Poland

3 Faculty of Mechanical Engineering, Lublin University of Technology, Nadbystrzycka 36 St, 20-618 Lublin, Poland
Nosal-Wiercińska et al. 2018). The degree of adsorption competition can depend on the potential of electrode, its charge as well as interactions in the layer of adsorbates.

6-Thioguanine (6TG) is an example of antimetabolite of natural purine bases whose action mechanism consists mainly in incorporation of the DNA and RNA chains in the form of nucleosides and blocking purine de novo biosynthesis. 6TG can act as an antiangiogenous molecule which is of significant importance in antitumorous therapy (Zochowska et al. 2016).

The study of 6-thioguanine adsorption at the mercury/ electrolyte interface could be interesting in relation to its activity at the biological interfaces. The addition of surfactants into the system can provide new information about interface structure, orientation of adsorbing electrode inactive molecules as well as interactions between them.

It is commonly known that surfaces of mammalian cells and other biological membranes carry an appreciable electrical potential. The electrical double layer formed in the immediate vicinity of the charged membrane-biological fluid interface can be regarded as essentially identical to that formed at the electrode surface-electrolyte solution interface (Cascales et al. 1998).

Adsorption associated with the mixed adsorption layers of 6-thioguanine-TritonX-100 and 6-thioguanine-Tween 80 in the solutions of different water activity was studied.

The choice of chlorate(VII) solution results from the fact that $\mathrm{ClO}_{4}^{-}$ions cause the greatest disruption in the water 
structure and slight adsorption of these ions on the mercury surface (Koryta et al. 1980).

Our previous studies on amino acids (Nosal-Wiercińska and Dalmata 2010; Nosal-Wiercińska 2012, 2013) confirmed the considerable influence of these substances and water activity on the adsorption parameters of the electrical double layer at the mercury/chlorate(VII) interface. In all the examined systems relative surface excesses of amino acids were proved to increase with the increase of electrode charge and adsorbate concentration; they were also found to depend on chlorates(VII) concentration. Moreover, the adsorption parameters changed along with the change of the supporting electrolyte concentration which points out to the competitive adsorption of amino acids and $\mathrm{ClO}_{4}^{-}$ions.

\section{Experimental}

\subsection{Materials and methods}

Analytical-grade reagents: 6-thioguanine (Fluka), $\mathrm{NaClO}_{4}$ (Fluka) and $\mathrm{HClO}_{4}$ (Fluka), Triton X-100 (Sigma-Aldrich) and Tween 80 (Sigma-Aldrich) were used without further purification. The solutions were prepared from freshly doubly-distilled water. Before the measurements the solutions were deaerated using high-purity nitrogen. Nitrogen was passed over the solution during the measurements.

2, 4 and $6 \mathrm{~mol} \mathrm{dm}^{-3}$ chlorate(VII) solutions, mixed at proper ratios $\left(\times \mathrm{mol} \mathrm{dm}{ }^{-3} \mathrm{NaClO}_{4}+1 \mathrm{~mol} \mathrm{dm}^{-3} \mathrm{HClO}_{4}\right.$ (where $0 \leq x \leq 5$ ) were used as a basic electrolyte.

The solutions were prepared just before the measurements. The concentrations of $6 \mathrm{TG}$ were in the range of $0.5-50 \times 10^{-3} \mathrm{~mol} \mathrm{dm}^{-3}$ whereas Triton X-100 and Tween 80 were in the range $1 \times 10^{-6}-1 \times 10^{-3} \mathrm{~mol} \mathrm{dm}^{-3}$.

The measurements were performed at $298 \mathrm{~K}$ in a threeelectrode cell containing: a dropping mercury electrode (CGMDE) with a controlled increase rate and a constant drop surface $\left(0.014740 \mathrm{~cm}^{2}\right)$, as a working electrode (MTM Poland); $\mathrm{Ag} / \mathrm{AgCl}$ (3 $\mathrm{M}$ saturated solution of $\mathrm{NaCl}$ ) as a reference electrode and a platinum spiral as an auxiliary electrode. Viscosity measurements were performed at $298 \mathrm{~K}$ using the rotational CVO 50 rheometer with the "double gap" measuring system (Bohlin Instruments).

The double layer capacity $\left(\mathrm{C}_{\mathrm{d}}\right)$ was measured using the impedance technique with an $\mu$ Autolab Fra 2/GPES (Version 4.9) frequency response analyzer (Eco Chemie, Utrecht, Netherlands). The reproducibility of the average capacity measurements was $\pm 0.5 \%$. For the whole polarisation range, the capacity dispersion was tested at different frequencies changing in the range $200-1000 \mathrm{~Hz}$. The equilibrium capacities were obtained by extrapolation of the measured capacity vs. the square root of the frequency to the zero frequency (Nosal-Wiercińska 2013).
The potential of zero charge $\left(E_{z}\right)$ was determined using a streaming electrode (Nosal-Wiercińska 2013) with the accuracy of $\pm 0.1 \mathrm{mV}$.

The surface tension at the potential of zero charge $\left(\gamma_{z}\right)$ was measured using the method of the highest pressure inside the mercury drop presented by Schiffrin (Nosal-Wiercińska 2013). The surface tension values were determined with an accuracy of $\pm 0.2 \mathrm{mN} \mathrm{m}^{-1}$.

The critical micelle concentration (CMC) was determined using the viscosity method. The measurements were made in the following systems: $2,4,6 \mathrm{~mol} \mathrm{dm}^{-3}$ chlorate(VII)-Triton $\mathrm{X}-100 ; 2,4,6 \mathrm{~mol} \mathrm{dm}^{-3}$ chlorate(VII)-Tween 80 and in the analogous systems containing 6-thioguanine. In the range of studied concentrations CMC was determined depending on viscosity of the studied solutions. A rapid change in the system viscosity was found at the concentration value corresponding to $\mathrm{CMC}$.

\section{Results and discussion}

Figure 1 shows the capacitance curves in $2 \mathrm{~mol} \mathrm{dm}^{-3}$ chlorates(VII) in the presence of 6-thioguanine. In the region of the "hump" potentials appearing in $2 \mathrm{~mol} \mathrm{dm}^{-3}$ chlorate(VII) without the studied substances $(\approx-200$ to $-800 \mathrm{mV}$ ). After the addition of 6-thioguanine to the solution, the height of this "hump" decreases. The increase in the concentration of studied substances causes further capacitive

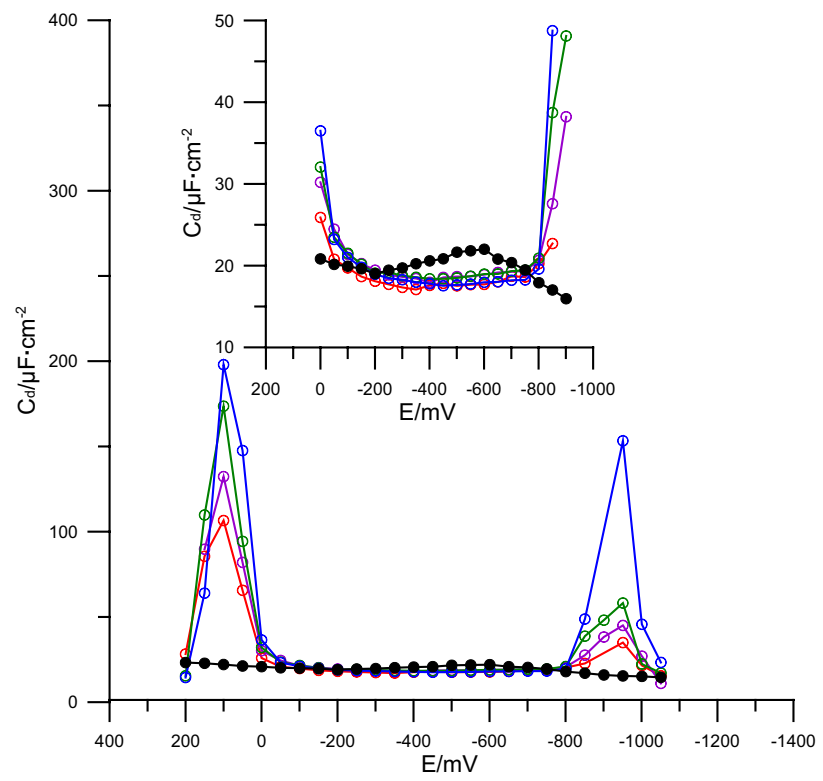

Fig. 1 Differential capacity-potential curves of the double electri-

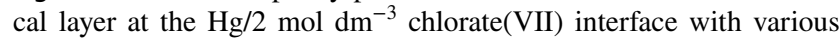
concentrations of 6-thioguanine: (filled circle with black) 0 , (open red circle) $5 \times 10^{-4}$, (open purple circle) $1 \times 10^{-3}$, (open green circle)

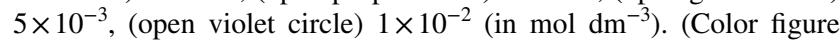
online) 
changes in the region of "hump" potentials. Such picture of capacity curves indicates strong adsorption properties of 6-thioguanine (Nosal-Wiercińska et al. 2018). In the region of higher potentials $(\approx 100 \mathrm{mV})$ the adsorption peaks occur in the presence of 6-thioguanine (Fig. 1), however, in the area of the most negative potentials about $-950 \mathrm{mV}$ the desorption peak appears. Both peaks increase with the increasing adsorbate concentration in the basic electrolyte solution. Similar relationships were obtained for more concentrated chlorates(VII).

Figures 2 and 3 show the capacitance curves in 2, $4 \mathrm{~mol}$ $\mathrm{dm}^{-3}$ chlorates(VII) in the presence of $1 \times 10^{-3} \mathrm{~mol} \mathrm{dm}^{-3}$ 6-thioguanine and the increasing Triton X-100 or Tween 80 concentrations. The addition of the surfactant to the basic electrolyte solution containing 6-thioguanine does not change the picture of capacity curves (Fig. 1). It should be noticed that the increase in Triton X-100 or Tween 80 concentration in the basic electrolyte results in the evident decrease of desorption peaks, even their disappearance. Peak of adsorption does not change its height. This should be associated with the effect of Triton X-100 or Tween 80 on adsorption equilibria formation. The analysis of the differential capacity curves course, in the case of the mixed adsorption layers of 6-thioguanine-TritonX-100 or 6-thioguanine-Tween 80 , reveals evident domination of 6-thioguanine in the formation of adsorption equilibrium. However,

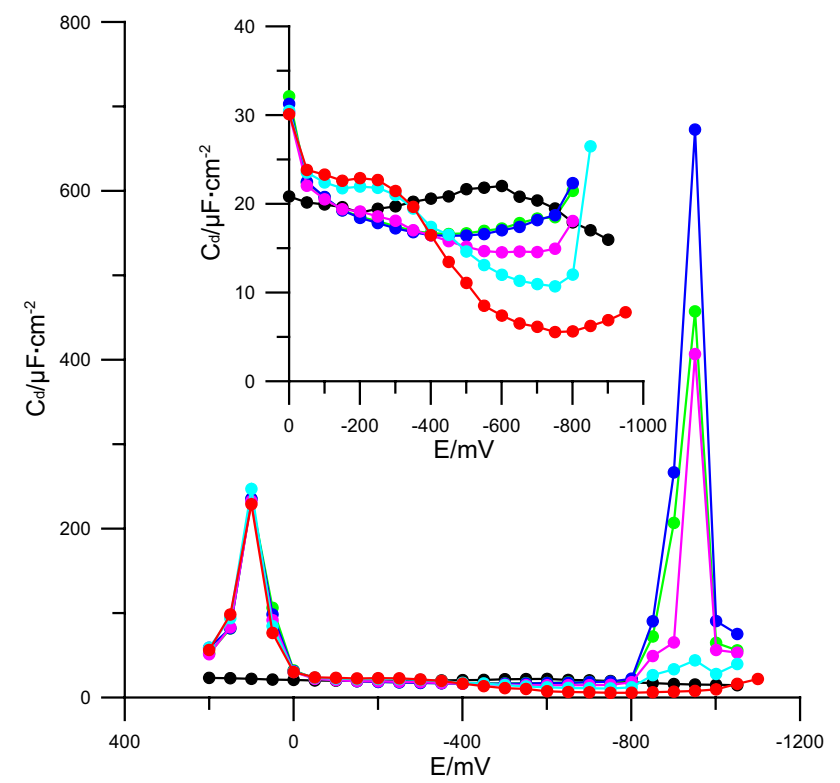

Fig. 2 Differential capacity-potential curves of the double electrical layer at the $\mathrm{Hg} / 2 \mathrm{~mol} \mathrm{dm}^{-3}$ chlorate(VII) interface with $1 \times 10^{-3} \mathrm{~mol}$ $\mathrm{dm}^{-3} 6$-thioguanine and with various concentrations of Triton X-100: (filled circle with black) 0 , (filled circle with navy blue) $2 \times 10^{-6}$, (filled circle with green) $1 \times 10^{-5}$, (filled circle with pink) $2 \times 10^{-5}$, (filled circle with cyan) $4 \times 10^{-5}$, (filled circle with red) $5 \times 10^{-5}$ (in $\left.\mathrm{mol} \mathrm{dm} \mathrm{dm}^{-3}\right)$. (Color figure online)

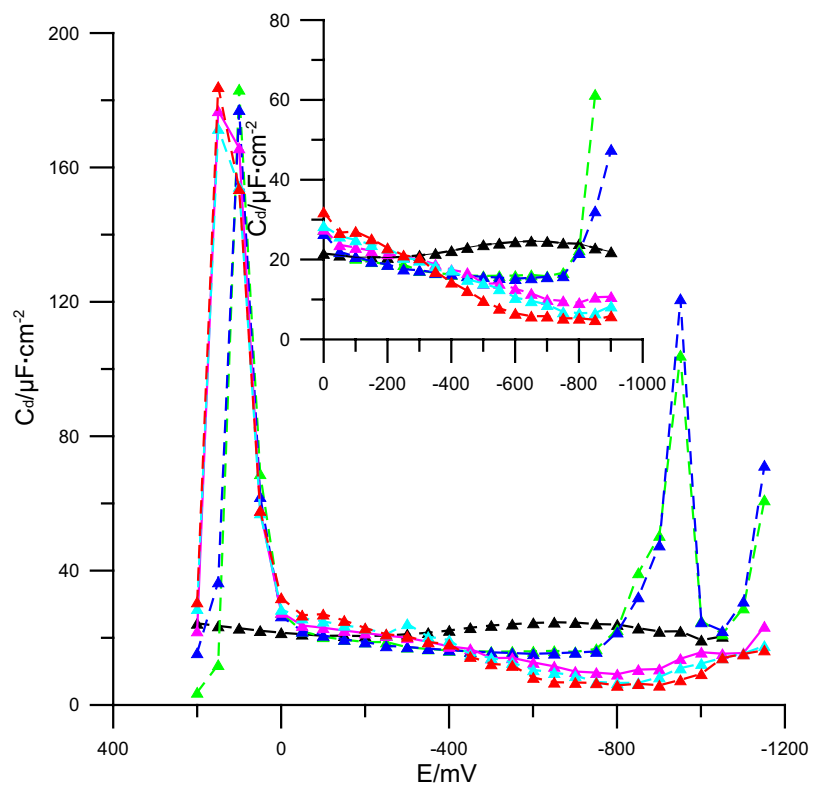

Fig. 3 Differential capacity-potential curves of the double electrical layer at the $\mathrm{Hg} / 4 \mathrm{~mol} \mathrm{dm}^{-3}$ chlorate(VII) interface with $1 \times 10^{-3} \mathrm{~mol}$ $\mathrm{dm}^{-3}$ 6-thioguanine as well as with various concentrations of Tween 80: (filled triangle with black) 0 , (filled triangle with navy blue) $2 \times 10^{-6}$, (filled triangle with green) $1 \times 10^{-5}$, (filled triangle with pink) $2 \times 10^{-5}$, (filled triangle with cyan) $4 \times 10^{-5}$, (filled triangle with red) $5 \times 10^{-5}$ (in mol dm${ }^{-3}$ ). (Color figure online)

one should not exclude mutual interactions of 6-thioguanine and the surfactant molecules leading to formation of a more less compact structure of adsorption layers (Gugała-Fekner et al. 2009).

For the identical 6-thioguanine or 6-thioguanine-Triton X-100 or 6-thioguanine-Tween 80 concentrations (Fig. 4a, $\mathrm{b}, \mathrm{c}$ ) with the increase of chlorate(VII) concentration the adsorption peaks do not change their position and height. Whereas the desorption peaks evidently decrease and even decay for the 6-thioguanine-Tween 80 system.

There are two reasons for the changes in the capacity curve: reorientation of water and changes in the electrostatic interactions between the adsorbed molecules (Parsons and Reeves 1981; Parsons 1981).

Tables 1, 2, 3, 4, 5 and 6 present the values of the potentials of zero charge and those of the surface tension at the zero charge potential for the studied systems. As follows from Tables 1, 2 and 3 the addition of 6-thioguanine to the 2, 4, $6 \mathrm{~mol} \mathrm{dm}$ chlorates(VII) solution causes shift of towards more negative potentials. This indicates adsorption of 6-thioguanine molecule oriented with the negative part towards the mercury surface (Gugała-Fekner et al. 2009).

Moreover with the increase in the 6-thioguanine concentration the values shift significantly towards more positive values of potentials. Such changes of with the increasing concentration suggest change of molecule orientation on the 


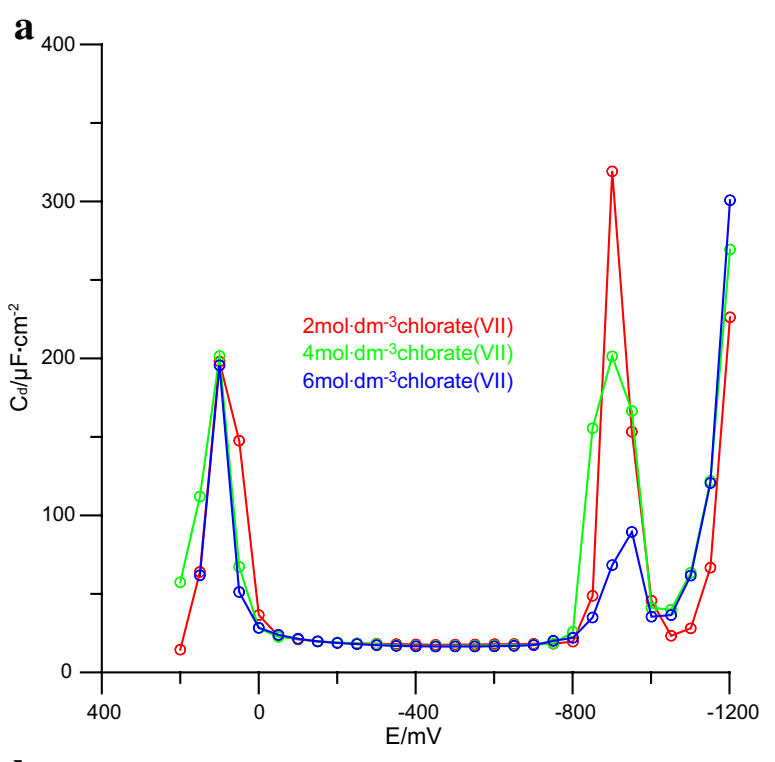

$\mathbf{b}_{400}$

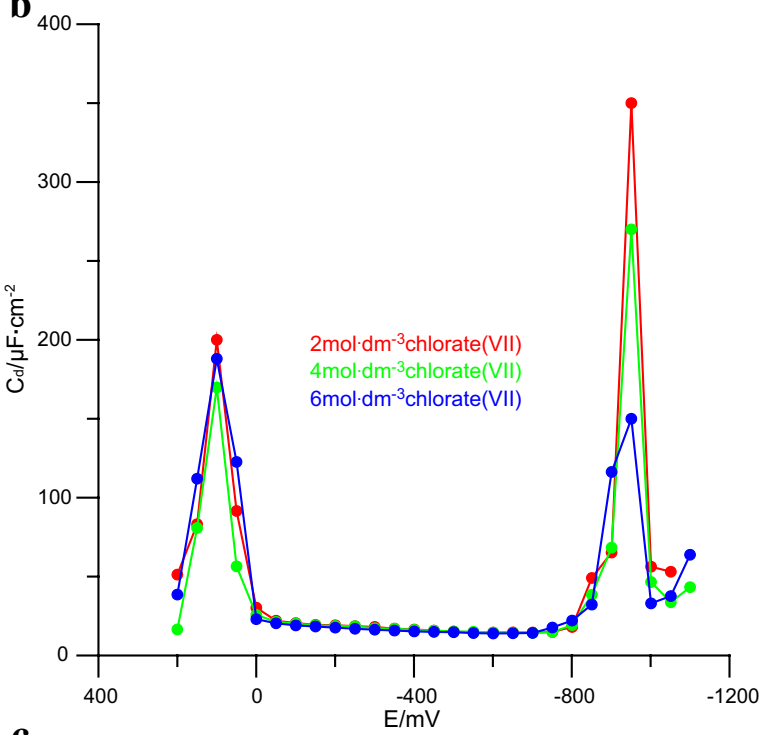

c

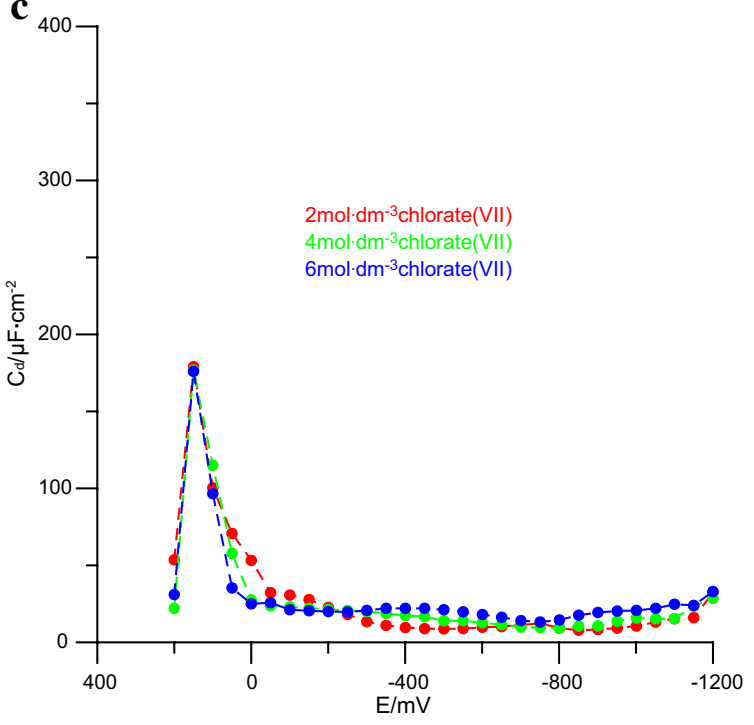

4 Fig. 4 Differential capacity-potential curves of the double electrical layer at the $\mathrm{Hg}$ /chlorate(VII) interface with $1 \times 10^{-3} \mathrm{~mol} \mathrm{dm}^{-3}$ 6-thioguanine (a) and with $1 \times 10^{-5}$ Triton X-100 (b) as well as with Tween 80 (c). Concentrations of chlorates(VII) are given in the figures

Table 1 Potential of zero-charge $E_{z}$ vs. $\mathrm{Ag} / \mathrm{AgCl}$ electrode and surface tension $\gamma_{z}$ for $E_{z}$ of $2 \mathrm{~mol} \mathrm{dm}^{-3}$ chlorates(VII) solutions + different 6-thioguanine systems

\begin{tabular}{lll}
\hline $10^{3} \mathrm{c} 6$-thioguanine $/ \mathrm{mol} \mathrm{dm}^{-3}$ & $-E_{z} / V$ & $\gamma_{z} / \mathrm{m} \mathrm{N} \mathrm{m}^{-1}$ \\
\hline 0 & 0.483 & 477.5 \\
0.5 & 0.524 & 475.6 \\
1.0 & 0.516 & 470.1 \\
5.0 & 0.510 & 462.7 \\
\hline
\end{tabular}

Table 2 Potential of zero-charge $E_{z}$ vs. $\mathrm{Ag} / \mathrm{AgCl}$ electrode and surface tension $\gamma_{z}$ for $E_{z}$ of $4 \mathrm{~mol} \mathrm{dm}^{-3}$ chlorates(VII) solutions + different 6-thioguanine systems

\begin{tabular}{lll}
\hline $10^{3} \mathrm{c} 6$-thioguanine $/ \mathrm{mol} \mathrm{dm}^{-3}$ & $-E_{z} / V$ & $\gamma_{z} / \mathrm{m} \mathrm{N} \mathrm{m}^{-1}$ \\
\hline 0 & 0.524 & 460.0 \\
0.5 & 0.544 & 459.0 \\
1.0 & 0.535 & 450.0 \\
5.0 & 0.520 & 446.2 \\
\hline
\end{tabular}

Table 3 Potential of zero-charge $E_{z}$ vs. $\mathrm{Ag} / \mathrm{AgCl}$ electrode and surface tension $\gamma_{z}$ for $E_{z}$ of $6 \mathrm{~mol} \mathrm{dm}{ }^{-3}$ chlorates(VII) solutions + different 6-thioguanine systems

\begin{tabular}{lll}
\hline $10^{3} \mathrm{c}$ 6-thioguanine $/ \mathrm{mol} \mathrm{dm}^{-3}$ & $-E_{z} / V$ & $\gamma_{z} / \mathrm{m} \mathrm{N} \mathrm{m}^{-1}$ \\
\hline 0 & 0.594 & 458.0 \\
0.5 & 0.620 & 456.0 \\
1.0 & 0.615 & 451.0 \\
5.0 & 0.608 & 449.3 \\
\hline
\end{tabular}

mercury surface. For the mixed adsorption layers of 6-thioguanine-Triton X-100 and 6-thioguanine-Tween 80 the shift of the values always towards more positive $\mathrm{z}$ potentials is observed (Tables 4, 5, 6). However, it should be noted that for the $2 \mathrm{~mol} \mathrm{dm}^{-3}$ chlorates(VII) solution at the constant concentration $1 \times 10^{-3} \mathrm{~mol} \mathrm{dm}^{-3}$ of 6-thioguanine the effect of shift is clearly marked in the presence of $3 \times 10^{-5} \mathrm{~mol}$ $\mathrm{dm}^{-3}$ for TritonX-100 and $4 \times 10^{-5} \mathrm{~mol} \mathrm{dm}^{-3}$ for Tween 80 (Table 4). These concentrations of surfactants correspond to the CMC values determined in the presence of 6TG. Drop in the CMC values in the presence of 6TG (CMC for Triton $\mathrm{X}-100=1 \times 10^{-4} \mathrm{~mol} \mathrm{dm}^{-3}$ and in the presence of 
Table 4 Potential of zero-charge $E_{z}$ vs. $\mathrm{Ag} / \mathrm{AgCl}$ electrode and surface tension $\gamma_{z}$ for $E_{z}$ of $2 \mathrm{~mol} \mathrm{dm}^{-3}$ chlorates (VII) solutions $+1 \times 10^{-3} \mathrm{~mol} \mathrm{dm}^{-3}$ 6-thioguanine + different surfactants concentration systems

\begin{tabular}{|c|c|c|c|c|}
\hline \multirow{2}{*}{$\begin{array}{l}1 \times 10^{-3} \mathrm{~mol} \mathrm{dm}^{-3} 6 \text {-thiogua- } \\
\text { nine }+10^{6} \mathrm{c}_{\text {surfactants }} / \mathrm{mol} \mathrm{dm}^{-3}\end{array}$} & \multicolumn{2}{|l|}{$-E_{z} / V$} & \multicolumn{2}{|l|}{$\gamma_{z} / \mathrm{m} \mathrm{N} \mathrm{m}^{-1}$} \\
\hline & TritonX-100 & Tween 80 & TritonX-100 & Tween 80 \\
\hline 0 & 0.516 & 0.516 & 470.1 & 470.1 \\
\hline 1 & 0.474 & 0.457 & 470.0 & 452.6 \\
\hline 2 & 0.471 & 0.450 & 469.0 & 451.7 \\
\hline 10 & 0.469 & 0.438 & 467.3 & 450.8 \\
\hline 20 & 0.463 & 0.425 & 463.0 & 447.8 \\
\hline 30 & 0.445 & 0.422 & 453.6 & 446.2 \\
\hline 40 & 0.435 & 0.399 & 448.0 & 436.1 \\
\hline 50 & 0.430 & 0.388 & 440.7 & 430.6 \\
\hline
\end{tabular}

Table 5 Potential of zero-charge $E_{z}$ vs. $\mathrm{Ag} / \mathrm{AgCl}$ electrode and surface tension $\gamma_{z}$ for $E_{z}$ of $4 \mathrm{~mol} \mathrm{dm}^{-3}$ chlorates (VII) solutions $+1 \times 10^{-3} \mathrm{~mol} \mathrm{dm}^{-3}$ 6-thioguanine + different surfactants concentration systems

\begin{tabular}{|c|c|c|c|c|}
\hline \multirow{2}{*}{$\begin{array}{l}1 \times 10^{-3} \mathrm{~mol} \mathrm{dm}^{-3} 6 \text {-thiogua- } \\
\text { nine }+10^{6} \mathrm{c}_{\text {surfactants }} / \mathrm{mol} \mathrm{dm}^{-3}\end{array}$} & \multicolumn{2}{|l|}{$-E_{z} / V$} & \multicolumn{2}{|l|}{$\gamma_{z} / \mathrm{m} \mathrm{N} \mathrm{m}^{-1}$} \\
\hline & TritonX-100 & Tween 80 & TritonX-100 & Tween 80 \\
\hline 0 & 0.535 & 0.535 & 450.0 & 450.0 \\
\hline 1 & 0.541 & 0.579 & 449.0 & 448.9 \\
\hline 2 & 0.540 & 0.572 & 449.0 & 448.0 \\
\hline 10 & 0.539 & 0.564 & 448.5 & 447.2 \\
\hline 20 & 0.537 & 0.559 & 448.2 & 447.0 \\
\hline 30 & 0.534 & 0.555 & 448.0 & 443.6 \\
\hline 40 & 0.532 & 0.545 & 447.9 & 440.0 \\
\hline 50 & 0.531 & 0.540 & 447.5 & 436.0 \\
\hline
\end{tabular}

Table 6 Potential of zero-charge $E_{z}$ vs. $\mathrm{Ag} / \mathrm{AgCl}$ electrode and surface tension $\gamma_{z}$ for $E_{z}$ of $6 \mathrm{~mol} \mathrm{dm}^{-3}$ chlorates (VII) solutions $+1 \times 10^{-3} \mathrm{~mol} \mathrm{dm}^{-3}$ 6-thioguanine + different surfactants concentration systems

\begin{tabular}{|c|c|c|c|c|}
\hline \multirow{2}{*}{$\begin{array}{l}1 \times 10^{-3} \mathrm{~mol} \mathrm{dm}^{-3} \\
\text { 6-thioguanine }+10^{6} \mathrm{c}_{\text {surfactants }} \\
\text { mol dm }\end{array}$} & \multicolumn{2}{|l|}{$-E_{z} / V$} & \multicolumn{2}{|l|}{$\gamma_{z} / \mathrm{m} \mathrm{N} \mathrm{m}^{-1}$} \\
\hline & TritonX-100 & Tween 80 & TritonX-100 & Tween 80 \\
\hline 0 & 0.615 & 0.615 & 451.0 & 451.0 \\
\hline 1 & 0.624 & 0.612 & 449.0 & 449.1 \\
\hline 2 & 0.620 & 0.610 & 448.9 & 447.8 \\
\hline 10 & 0.619 & 0.608 & 448.7 & 446.2 \\
\hline 20 & 0.617 & 0.605 & 448.4 & 446.0 \\
\hline 30 & 0.619 & 0.600 & 448.2 & 447.0 \\
\hline 40 & 0.610 & 0.588 & 447.7 & 445.0 \\
\hline 50 & 0.608 & 0.580 & 447.5 & 440.7 \\
\hline
\end{tabular}

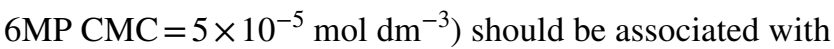
competitive adsorption as well as between mixed micelles (Nosal-Wiercińska et al. 2018).

Also the synergistic effect can be excluded (Wiśniewska et al. 2012; Szymczyk and Jańczuk 2008).

Such dependences are not observed in 4, $6 \mathrm{~mol} \mathrm{dm}^{-3}$ chlorates(VII) solution which evidences a significant role of $\mathrm{ClO}_{4}{ }^{-}$ions in the adsorption-desorption processes.

The values of surface tension at the zero charge potential (Tables 1, 2, 3, 4, 5, 6) decrease for all studied systems as proved by the adsorption phenomenon.
Essential changes of the value for the $2 \mathrm{~mol} \mathrm{dm}^{-3}$ chlorates(VII) solution in the presence of constant concentration $1 \times 10^{-3} \mathrm{~mol} \mathrm{dm}^{-3} 6$-thioguanine for the concentration $3 \times 10^{-4} \mathrm{~mol} \mathrm{dm}^{-3}$ for TritonX-100 and $4 \times 10^{-4} \mathrm{~mol}$ $\mathrm{dm}^{-3}$ for Tween 80 (Table 4 ) also point out to the changes in the adsorption layer associated with appearance of hemimicelles or micelles (Munoz et al. 1992; Sotiropoulos et al. 1993). 


\section{Conclusions}

The results presented in the paper point out to the distinct influence of supporting electrolyte concentration on the formation of adsorption equilibrium in the case of mixed adsorption layers. The adsorption parameters indicate a distinct domination of specifically adsorbed 6-thioguanine in formation of adsorption equilibria as well as change of orientation of the molecules adsorbed on the electrode surface. This was found only for $2 \mathrm{~mol} \mathrm{dm}^{-3}$ chlorates(VII) solution at the concentrations of surfactants far below the $\mathrm{CMC}$, where no the multilayer adsorption occurs which results in small two-dimensional surface micelles. At the concentrations above the CMC, multilayer adsorption can take place. The changes of determined parameters in the function of the supporting electrolyte concentration point out to the participation of $\mathrm{ClO}_{4}^{-}$ions in the adsorption processes, or existence of the electrostatic interactions between the dipoles of $\mathrm{H}_{2} \mathrm{O}$ and 6-thioguanine-Triton $\mathrm{X}-100$ or 6-thioguanine-Tween 80.

Open Access This article is distributed under the terms of the Creative Commons Attribution 4.0 International License (http://creativeco mmons.org/licenses/by/4.0/), which permits unrestricted use, distribution, and reproduction in any medium, provided you give appropriate credit to the original author(s) and the source, provide a link to the Creative Commons license, and indicate if changes were made.

\section{References}

Cascales, J.J.L., De la Torre, J.G., Marrink, S.J., Berendsen, H.J.C.: Molecular dynamics simulation of a charged biological membrane. J. Chem. Phys. 104, 2713-2720 (1998)

Fouda, A.S., Attia, A.M., Rashed, A.M.: Corrosion inhibition of mild steel in agueous solutions using non-ionic surfactants Prot. Mater. Phys. Chem. Surf. 53, 743-752 (2017)

Fuchs-Godec, R.: Inhibitory effect of non-ionic surfactants of the TRITON-X series on the corrosion of carbon steel in sulphuric acid. Electrochim. Acta 52, 4974-4981 (2007)

Gugała-Fekner, D., Sieńko, D., Nieszporek, J., Klin, M., Saba, J.: Mixed adsorption layers of $0.1 \mathrm{M}$ tert-butanol-tetramethylthiourea at the interface of $\mathrm{Hg}$ /aqueous perchlorate solutions. J. Colloid Inter. Sci. 332, 291-297 (2009)

Koryta, J., Dvorak, J., Bohackova, V.: Elektrochemia PWN, Warszawa (1980)

Munoz, E., Rodriguez-Amaro, R., Ruiz, J.J., Avila, J.L., Camacho, L.: Inhibition of the electrode reduction of an adsorbed species by the competitive adsorption of surfactant. Study of the cefazolin-Triton $\mathrm{X}-100$ system at the $\mathrm{Hg}-\mathrm{H}_{2} \mathrm{O}$ interface. J. Electroanal. Chem. 324, 359-374 (1992)
Nieszporek, J., Sieńko, D., Gugała-Fekner, D., Klin, M.: Properties of the mixed adsorption layer: neutral detergent-tetramethylthiourea at interface electrode/solution. Turk. J. Chem. 36, 841-851 (2012)

Nosal-Wiercińska, A.: Adsorption of cystine at mercury/aqueous solution of chlorate(VII) interface in solutions of different water activity. Cent. Eur. J. Chem. 10, 1290-1300 (2012)

Nosal-Wiercińska, A.: The influence of water activity on double layer parameters on the interface mercury/chlorates (VII) in the presence of cysteine. Croat. Chem. Acta 86, 159-164 (2013)

Nosal-Wiercińska, A.: Intermolecular interactions in systems containing $\mathrm{Bi}(\mathrm{III})-\mathrm{ClO}_{4}^{-}-\mathrm{H}_{2} \mathrm{O}$-selected amino acids in the aspect of catalysis of Bi(III) electroreduction. Electroanalysis 26, 1013-1023 (2014)

Nosal-Wiercińska, A., Dalmata, G.: Adsorption of methonine at mercury/aqueous solution of chlorate(VII) interface; dependence on the supporting electrolyte concentration. Electroanalysis 22 , 2081-2086 (2010)

Nosal-Wiercińska, A., Kaliszczak, W., Grochowski, M., Wiśniewska, M., Klepka, T.: Effects of mixed adsorption layers of 6-mercaptopurine-Triton X-100 and 6-mercaptopurine-Tween 80 on the double layer parameters at the mercury/chlorates(VII) interface. J. Mol. Liq. 253, 143-148 (2018)

Parsons, R.: The electrical double layer at solid/liquid interfaces. J. Electroanal. Chem. 118, 3-18 (1981)

Parsons, R., Reeves, R.M.: Molecular models for the structure of solvent in an interphase. J. Electroanal. Chem. 123, 141-149 (1981)

Qu, J.-E., Guo, X.-P.: Influence of dodecylamine on accelerated dissolution of copper-Nickel alloy initiated by AFM tip-surface interaction. Corros. Sci. Prot. Technol. 17, 297-300 (2005)

Sotiropoulos, S., Nikitas, P., Papadopoulos, N.: Interfacial micellization of cetyl-dimethyl-benzylammonium chloride and Tween 80 at the $\mathrm{Hg} / \mathrm{electrolyte}$ solution interphase. J. Electroanal. Chem. 356, 225-243 (1993)

Szymczyk, K., Jańczuk, B.: Wettability of a glass surface in the presence of two nonionic surfactant mixtures. Langmuir 24, 7755$7760(2008)$

Taffa, D.H., Hamm, I., Dunkel, C., Sinev, I., Bahnemann, D., Wark, M.: Electrochemical deposition of $\mathrm{Fe}_{2} \mathrm{O}_{3}$ in the presence of organic additives: a route to enhanced photoactivity. RSC Adv. 5, 103512103522 (2015)

Wiśniewska, M., Chibowski, S., Urban, T.: Effect of the type of polymer functional groups on the structure of its film formed on the alumina surface—suspension stability. Reactive Funct Polym. 72, 791-798 (2012)

Zeng, Z., Chang, K., Kubal, J., Markovic, N.M., Greeley, J.: Stabilization of ultrathin (hydroxy)oxide films on transition metal substrates for electrochemical energy conversion. Nat. Energy 2, 17070 (2017)

Zochowska, D., Zegarska, J., Hryniewiecka, E., Samborowska, E., Jazwiec, R., Tszyrsznic, W., Borowiec, A., Dadlez, M., Paczek, L.: Determination of concentrations of azathioprine metabolites 6-thioguanine and 6-methylmercaptopurine in whole blood with the use of liquid chromatography combined with mass spectrometry. Transplant. Proc. 48, 1836-1839 (2016) 